\title{
Описание изотермы сорбции тритерпенового сапонина на природных сорбентах
}

\author{
® 2019 Мироненко Н.В., Смусева С.О., Коцарева Т.В., Селеменев В.Ф. \\ Воронежский государственный университет, Воронеж
}

Поступила в редакцию 1.10.2019 г.

DOI: $10.17308 /$ sorpchrom.2020.20/2378

Известно большое число публикаций, посвященных исследованию сорбции биологически активных веществ на синтетических и природных сорбентах. Одними из таких соединений являются тритерпеновые сапонины, широко применяемые в качестве лекарственных средств природного происхождения. Данная работа посвящена оценке применимости существующих моделей для интерпретации экспериментальных данных по адсорбции сапонина на природных сорбентах.

Объектом исследования являлся образец сапонина Quillaja Saponaria Molina производства США. Хитозан производства ООО «Фармакон Продакшн» (г. Санкт-Петербург) является аминополисахаридом, производным линейного полисахарида, макромолекулы которого состоят из связанных $\beta$ (1-4) D-глюкозаминовых звеньев и $\mathrm{N}$-ацетил-D-глюкозамина, используется как биологически активная добавка к пище. В качестве углеродного материала использовали таблетки активированного угля производства ОАО «Фармстандарт-Лексредства».

Сорбционное равновесие в системах «сапонин - хитозан», «сапонин - уголь» изучали при температуре $298 \pm 2$ К в статических условиях методом переменных концентраций. Экспериментально получены изотермы сорбции сапонина хитозаном и активированным углем. На первом участке изотермы линейны. В основе механизма взаимодействия сапонина с хитозаном лежит ионнокоординационное взаимодействие с аммониевой группой полисахарида, с углеродным материалом дальнодействующие гидрофобные силы, которые обусловливают ассоциацию молекул сапонинов и притяжение их к гидрофобной поверхности сорбента. Второй участок изотерм различен: на хитозане наблюдается перегиб, выходящий на плато, на углеродном материале в области концентраций - локальный минимум, затем рост сорбционного параметра на обеих изотермах. Отклонение формы изотермы от линейной на данном участке характеризует конкурентный процесс мицеллообразования и сорбционного поглощения на поверхности сорбента, характеризуемый величинами энергий адсорбции и ассоциации. В зависимости от получаемых значений указанных параметров на кривой наблюдается выход на плато или локальный минимум, обусловленный превалированием мицеллообразующих сил над энергией сорбционного поглощения. В третьей области значения сорбционных параметров резко возрастают, не выходя на плато, что обусловлено образованием слоисто-пластинчатых агрегатов в адсорбционном слое.

С учетом формы равновесных кривых были промоделированы экспериментальные результаты с использованием простых адсорбционных изотерм. Рассчитаны величины сорбционных параметров. Высокие значения коэффициентов корреляции $\left(\mathrm{R}^{2}\right)$ позволяют применять уравнение Генри для количественного описания изотермы сорбции хитозаном на начальном участке, а для анализа всей изотермы использовать теорию БЭТ, учитывающую полимолекулярный характер сорбции. Сорбция сапонина на углеродном материале описывается уравнением Ленгмюра в диапазоне 0.02-1 ммоль/дм ${ }^{3}$ и уравнением БЭТ в диапазоне 2-17 ммоль/дм³.

Полученные результаты по описанию изотерм сорбции сапонина согласуются с предложенным механизмами его поглощения природными сорбентами и могут быть использованы для обоснования возможного изменения его фармакокинетических характеристик в иммобилизованном состоянии.

Ключевые слова: сапонин, хитозан, уголь, сорбция, ассоциация, модели Генри, Ленгмюра, Фрейндлиха, БЭТ, Редлиха-Петерсона. 


\section{Введение}

Известно большое число публикаций, посвященных исследованию сорбции биологически активных веществ на синтетических и природных сорбентах [1-2]. Одними из таких соединений являются тритерпеновые сапонины - производные квиллайевой кислоты, широко применяемые в качестве лекарственных средств природного происхождения [3-4]. В качестве носителя (матрицы) могут использоваться классические сорбенты углеродного происхождения. Связывание и выведение из организма токсичных веществ позволяет использовать активные угли для иммобилизации широкого круга соединений органической и неорганической природы [5]. Хитозан, полимер, обладающий высокими сорбционными свойствами [6], также может быть использован в качестве носителя лекарственных препаратов. Исследование равновесных характеристик сорбционного поглощения в рамках применения существующих моделей $[2,7]$ позволит уточнить механизм связывания данных соединений и оценить возможное изменение фармакокинетических характеристик гликозидов в фазе биополимера.

Настоящая работа посвящена оценке применимости существующих моделей для интерпретации экспериментальных данных по адсорбции сапонина на природных сорбентах.

\section{Эксперимент}

Объектом исследования являлся товарный образец сапонина Quillaja Saponaria Molina производства США, который согласно экспериментальным и литературным данным, обладает поверхностной активностью [8]. Структурная формула приведена на рис. 1.

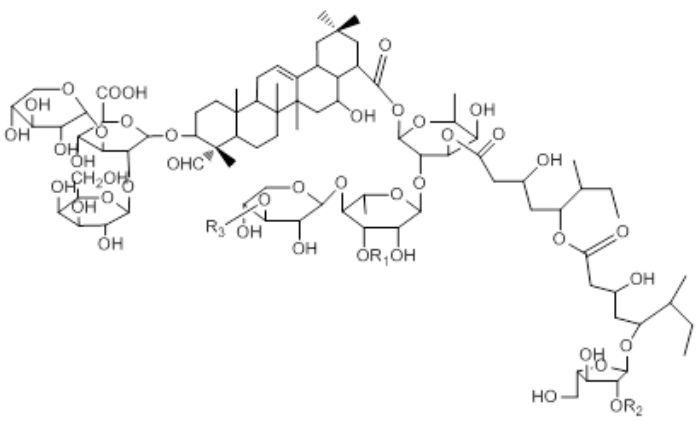

Рис. 1. Структурная формула индивидуального сапонина

Quillaja Saponaria Molina $\left(\mathrm{R}_{1}-\mathrm{C}_{9} \mathrm{H}_{12} \mathrm{O}_{9}, \mathrm{R}_{2}-\mathrm{C}_{6} \mathrm{H}_{12} \mathrm{O}_{5}, \mathrm{R}_{3}-\mathrm{C}_{5} \mathrm{H}_{10} \mathrm{O}_{5}\right.$ (апиоза))

Критическая концентрация мицеллообразования: $\mathrm{C}_{\text {Ккм1 }}=0.26-0.35$ ммоль/дм ${ }^{3}$, $\mathrm{C}_{\text {Ккм2 }}=4.35$ ммоль/дм ${ }^{3}[9]$.

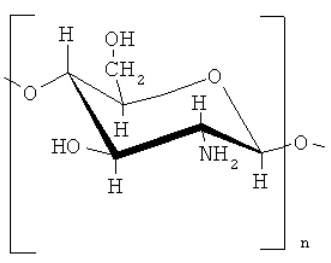

Рис. 2. Структурная формула звена хитозана

В качестве сорбента выступал хитозан, используемый как биологически активная добавка к пище, производства ООО «Фармакон Продакшн» (г. Санкт- 
Петербург). Строение элементарного звена хитозана показано на рис. 2. Средняя молекулярная масса 250-300 кДа, степень дезацетилирования 89.6\%.

В качестве углеродного материала использовали таблетки активированного угля производства ОАО «Фармстандарт-Лексредства». Суммарная площадь поверхности $805 \mathrm{~m}^{2} / \Gamma$, суммарный объем пор $\mathrm{V}_{\mathrm{s}}=2.38$.

Сорбционное равновесие в системах «сапонин - хитозан», «сапонин - уголь» изучали при температуре $298 \pm 2$ К в статических условиях методом переменных концентраций. Навески сорбента массой $0.2 \pm 0.0002$ г в воздушно-сухом состоянии заливали в конических колбах с притертой крышкой растворами сапонина объемом $200 \mathrm{~cm}^{3}$ с концентрациями 0.01-17.00 ммоль/дм³ ${ }^{3}$. Содержимое колб выдерживали при перемешивании в течение 4 часов до установления равновесия в системе. Время, необходимое для установления равновесия, определяли в предварительных кинетических экспериментах [10]. Затем отбирали аликвоты и анализировали на содержание сапонина спектрофотометрически по методике [11].

\section{Обсуждение результатов}

Структура адсорбционного слоя поверхностно-активных веществ на твердых сорбентах косвенно выражается в форме изотермы сорбции [12]. Экспериментально полученные изотермы сорбции сапонина хитозаном и активированным углем при низких концентрациях равновесного раствора линейны (рис. 3).
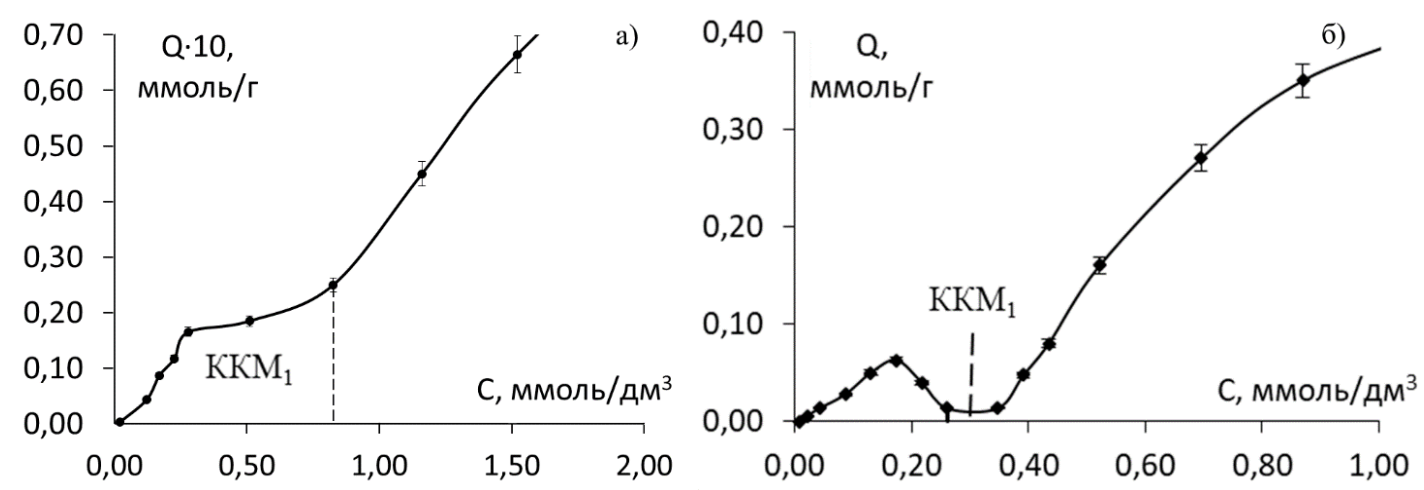

Рис. 3. Изотерма сорбции сапонина: а) хитозаном $\mathrm{C}=0.02-2.00$ ммоль/дм ${ }^{3}$, б) углеродным материалом $\mathrm{C}=0.02-1.00$ ммоль/дм ${ }^{3}$

В основе механизма взаимодействия сапонина с хитозаном лежит ионнокоординационное взаимодействие $\mathrm{c}$ аммониевой группой полисахарида, $\mathrm{c}$ углеродным материалом - дальнодействующие гидрофобные силы, которые обусловливают ассоциацию молекул сапонинов и притяжение их к гидрофобной поверхности сорбента. Второй участок изотерм $\left(\mathrm{C}=0.28-0.82\right.$ ммоль/дм $\left.{ }^{3}\right)$ различен: на хитозане наблюдается перегиб, выходящий на плато, на углеродном материале в области концентраций $\mathrm{C}=0.26-0.35$ ммоль/дм ${ }^{3}$ - локальный минимум, затем рост сорбционного параметра на обеих изотермах (рис. 4).

Отклонение формы изотермы от линейной на данном участке характеризует конкурентный процесс мицеллообразования и сорбционного поглощения на поверхности сорбента, характеризуемый величинами энергий адсорбции и ассоциации. В зависимости от получаемых значений указанных параметров на кривой наблюдается выход на плато или локальный минимум, обусловленный превалированием мицеллообразующих сил над энергией сорбционного поглощения [13]. 

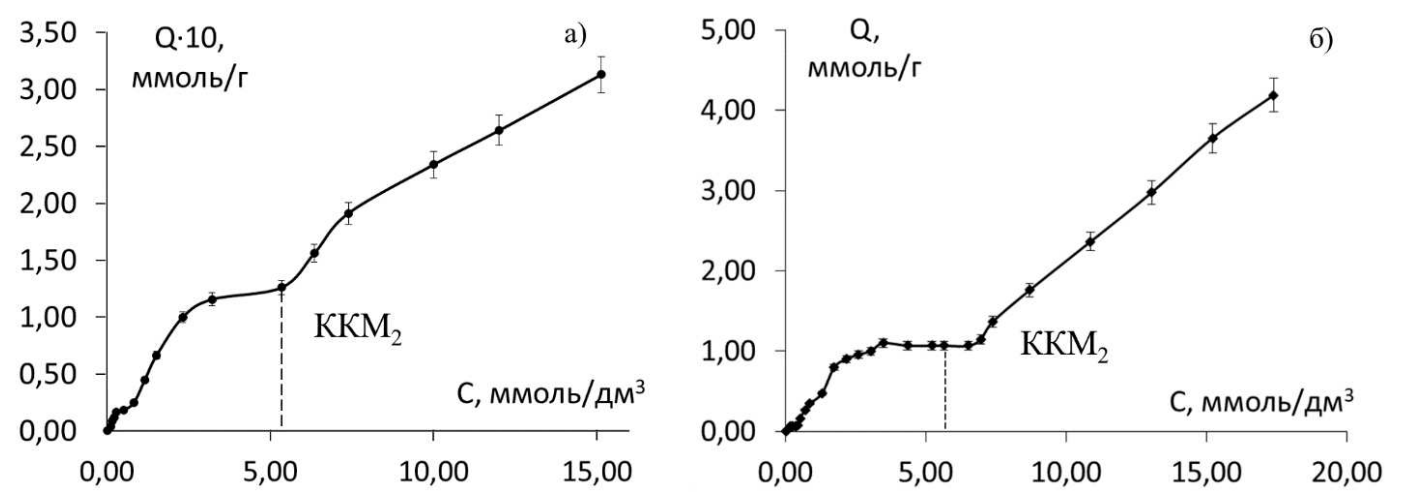

Рис. 4. Изотерма сорбции сапонина: а) хитозаном C=0.02-15.00 ммоль/дм ${ }^{3}$, б) углеродным материалом $\mathrm{C}=0.02-17.00$ ммоль/дм ${ }^{3}$

Аналогичный ход кривых наблюдается в области реструктуризации мицелл сапонина при больших концентрациях его в растворе. Формирование полимолекулярного адсорбционного слоя для данной области равновесных концентраций, возможно за счет образования большого числа трехмерных сферических ассоциатов [13]. В области концентрации раствора сапонина $\mathrm{C}=5.35-15.13$ ммоль/дм³ (третья область) значения сорбционных параметров резко возрастают, не выходя на плато, что обусловлено образованием слоисто-пластинчатых агрегатов в адсорбционном слое [13]. Данная структурная перегруппировка открывает практически неограниченные возможности для роста фактора ассоциации таких мицелл и, следовательно, для увеличения сорбции.

С учетом формы равновесных кривых были промоделированы экспериментальные результаты с использованием простых адсорбционных изотерм. Изотерма Генри характеризует адсорбцию при малых концентрациях адсорбтива. Полученное на основе закона Генри уравнение (табл. 1) и соответствующая ему линейная зависимость адсорбции сапонина от концентрации на начальном участке изотермы соблюдается лишь приближенно, но это приближение, судя по высокому значению коэффициента корреляции $\left(\mathrm{R}^{2}=0.974\right)$, бывает достаточным для практики.

Таблица 1. Модели, применяемые для описания изотерм сорбции сапонина

\begin{tabular}{|c|c|c|}
\hline Модель & Уравнение & Линейная форма \\
\hline Генри & $Q=K_{d} \cdot C$ & $\frac{C_{p}}{Q}=\frac{1}{K_{L} \cdot Q_{\infty}}+\frac{C_{p}}{Q_{\infty}}$ \\
\hline Ленгмюра & $Q=Q_{\infty} \cdot \frac{K_{L}}{1+K_{L}}$ & $\ln Q=\ln K_{F}+\frac{1}{n} \ln C_{p}$ \\
\hline Фрейндлиха & $Q=K_{F} \cdot C_{p}^{1 / n}$ & $C_{p}$ \\
\hline БЭТ & $Q=\frac{Q_{\infty} \cdot K_{L} \cdot C_{p}}{\left(1-K_{S} \cdot C_{p}\right) \cdot\left(1-K_{S} \cdot C_{p}+K_{L} \cdot C_{p}\right)}$ & $\left.\frac{K_{L}-K_{S}}{Q_{\infty} K_{L}}\right) \cdot C_{p}+\frac{1}{Q_{\infty} K_{L}}$ \\
\hline Редлиха-Петерсона & $Q=\frac{K_{R} C_{p}}{1+a_{R} C_{p}^{\beta}}$ & $\ln \left(K_{p} \frac{C_{p}}{Q}-1\right)=\ln a_{R}+\beta \ln C_{p}$ \\
\hline
\end{tabular}

где $\mathrm{K}_{\mathrm{d}}$ - константа уравнения Генри, дм ${ }^{3} / \Gamma ; \mathrm{Q}$ - количество сорбируемого сапонина, ммоль/г; $\mathrm{Q}_{\infty}$ - предельное количество сорбированного сапонина, ммоль/г; $\mathrm{K}_{\mathrm{F}}-$ константа равновесия уравнения Фрейндлиха, относящаяся к адсорбционной емкости; $1 / \mathrm{n}$ - параметр, указывающий на интенсивность взаимодействия адсорбент - адсорбат, $\mathrm{C}_{\mathrm{P}}$ - равновесная концентрация сапонина, ммоль/дм ${ }^{3}$; $\mathrm{K}_{\mathrm{L}}$ - константа сорбционного равновесия, характеризующая интенсивность сорбции, дм ${ }^{3} / \mathrm{Mмоль;}^{\circ}$

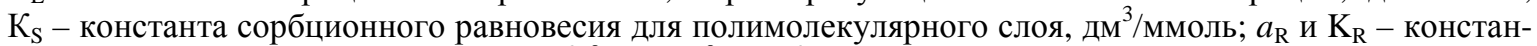
ты изотермы Редлиха-Петерсона, $\left(\text { дм }^{3}\right)^{\beta} /$ ммоль $^{\beta}$ и дм ${ }^{3} / \Gamma$ соответственно; $\beta$ - константа, значение которой должно лежать в интервале $0<\beta<1$. 
Теория Ленгмюра позволяет учесть наиболее сильные отклонения от закона Генри, связанные с ограниченностью адсорбционного объема или поверхности адсорбента. Ограниченность этого параметра приводит к адсорбционному насыщению поверхности адсорбента по мере увеличения концентрации распределяемого вещества [14]. Константы уравнения были рассчитаны из наклона и пересечения прямых на графике в соответствующих координатах линейного уравнения $1 / \mathrm{Q}$ от $1 / \mathrm{C}_{\mathrm{p}}$ (табл.2).

Описание изотермы на хитозане по модели Ленгмюра дало неудовлетворительные результаты (отрицательные значения сорбционного параметра), что свидетельствует о её неприменимости к описанию сорбции на выбранном энтеросорбенте. Модель Ленгмюра основана на однородности по энергии энтальпии всех сорбционных центров [15]. Установлено [16], что пространственно электростатическое взаимодействие осуществляется не с каждой аминогруппой хитозана, а вследствие стерических препятствий и наличия только одной карбоксильной группы в составе глюкуроновой кислоты молекулы сапонина, с каждой пятой или шестой молекулой цепочки хитозана. Спиралевидный тип конформации данного сорбента, образованный за счет внутримолекулярных связей, является одним из факторов, определяющих механизм его взаимодействия с сапонином и причиной энергетической неоднородности сорбционных центров связывания.

Уравнение изотермы модели Фрейндлиха используется для описания адсорбции на гетерогенной поверхности. Так как адсорбционные центры по этой модели обладают различными величинами энергии, то в первую очередь происходит заполнение активных сорбционных центров с максимальной энергией [17].

Модель БЭТ [18] предусматривает полислойное заполнение поверхности адсорбатом, причем активные центры обладают одинаковыми значениями энергии. Полислои могут образовываться на разных участках поверхности, как до заполнения монослоя, так и после него. Параметры уравнения БЭТ $\left(\mathrm{Q}_{\infty}\right.$ и $\left.\mathrm{K}_{\mathrm{L}}\right)$ находили графически, используя уравнение в линейной форме (табл. 1).

Полученные величины коэффициентов корреляции на двух участках изотермы свидетельствуют о возможности образования полислоев сорбата в диапазоне равновесных концентраций больших $\mathrm{KKM}_{1}$, и, в целом, подтверждают рассмотренный выше механизм поглощения сапонина.

Модель Редлиха-Петерсона [19], возможность применения которой была рассмотрена в работе [2], совмещает модели Фрейндлиха и Ленгмюра и предусматривает, кроме гетерогенности поверхности сорбента, также наличие определенного числа адсорбционных центров с одним и тем же адсорбционным потенциалом.

Надо отметить, что уравнение Редлиха-Петерсона содержит три константы, и поэтому воспользоваться его линейной формой для определения констант невозможно. В этом случае мы использовали процедуру минимизации (OriginPro 7.5) [20]. Величины полученных сорбционных параметров приведены в таблице 2.

Таблица 2. Значения сорбционных параметров

\begin{tabular}{|c|c|c|c|c|c|c|}
\hline \multicolumn{3}{|c|}{ Хитозан } & \multicolumn{4}{|c|}{ Углеродный сорбент (ОУ-А) } \\
\hline \multicolumn{3}{|c|}{ Модель Генри } & \multicolumn{4}{|c|}{ Модель Ленгмюра } \\
\hline \multicolumn{2}{|l|}{$\mathrm{K}_{\mathrm{d}}, \not \mathrm{M}^{3} / \Gamma$} & $\mathrm{R}^{2}$ & \multicolumn{2}{|c|}{$\mathrm{K}_{\mathrm{L}}$, дм³/ммоль $^{3} /$ мм } & \multicolumn{2}{|c|}{$\mathrm{R}^{2}$} \\
\hline \multicolumn{2}{|l|}{0.63} & 0.97 & \multicolumn{2}{|l|}{108.90} & \multicolumn{2}{|c|}{0.99} \\
\hline \multicolumn{7}{|c|}{ Модель БЭТ } \\
\hline $\mathrm{K}_{\mathrm{L}}$, дм$^{3} /$ ммоль & $\mathrm{K}_{\mathrm{S}}$, дм$^{3} /$ ммоль & $\mathrm{R}^{2}$ & $\mathrm{~K}_{\mathrm{L}}$, дм$^{3} /$ ммоль & & & $\mathrm{R}^{2}$ \\
\hline 0.99 & 0.04 & 0.98 & 2.72 & & & 0.98 \\
\hline
\end{tabular}


Судя по данным таблицы, высокие значения коэффициентов корреляции $\left(\mathrm{R}^{2}\right)$ позволяют применять уравнение Генри для количественного описания изотермы сорбции хитозаном на начальном участке, а для анализа всей изотермы использовать теорию БЭТ, учитывающую полимолекулярный характер сорбции.

Сорбция сапонина на углеродном материале описывается уравнением Ленгмюра в диапазоне 0.02-1.00 ммоль/дм ${ }^{3}$ и уравнением БЭТ в диапазоне 2.0017.00 ммоль/дм ${ }^{3}$. Количественной мерой сродства сапонина к поверхности угля служат величины констант адсорбционного равновесия уравнений Ленгмюра и БЭТ, подтверждающие выдвинутые ранее предположения [21] о механизме сорбции на активированном угле. Константы $\mathrm{K}_{\mathrm{L}}$ Ленгмюра и $\mathrm{K}_{\mathrm{L}}$ БЭТ имеют максимальное значение, тем самым подтверждая концепцию о большом сродстве молекул сапонина к поверхности активированного угля.

\section{Заключение}

Изотермы сорбции сапонина на хитозане и углеродном материале были обработаны моделями изотерм Генри, Ленгмюра, Фрейндлиха, Редлиха - Петерсона и БЭТ. Установлено, что сорбция сапонина из разбавленных растворов наилучшим образом описывается моделью Генри при использовании хитозана в качестве сорбента. Сорбция на углеродном материале описывается моделью Ленгмюра, что соответствует образованию мономолекулярного сорбционного слоя. Также возможно применение модели БЭТ для описания всей изотермы при сорбции как на хитозане, так и на углеродном сорбенте.

Полученные результаты по описанию изотерм сорбции сапонина согласуются с предложенными механизмами его поглощения природными сорбентами и могут быть использованы для обоснования возможного изменения его фармакокинетических характеристик в иммобилизованном состоянии.

\section{Список литературы}

1. Кузнецов В.А., Сливкин А.И., Лапенко В.Л., Болгов А.А. // Вестник МИТХТ. 2009. № 3. C. 97-102.

2. Котова Д.Л., Фам Тхи Гам, Крысанова Т.А., Васильева С.Ю. и др. // Сорбционные и хроматографические прочессы. 2014. Т. 14. № 4. C. 572-577.

3. Hostettmann K., Marston A. Saponins. Cambridge: Cambridge University Press. 1995. $548 \mathrm{p}$.

4. Атаманова С.А., Брежнева Т.А., Сливкин А.И., Николаевский В.А. и др. // Хим.-фарм. журн. 2005. Т. 39. № 12. С. 2931.

5. Коваленко Г.А., Кузнецова Е.В. // Химико-фармачевтический журнал. 2000. Т. 34. № 6. C. 45-49.

6. Скрябин К.Г. Хитин и хитозан: получение, свойства и применение / Под ред. К.Г. Скрябина, Г.А. Вихоревой, В.П. Варламова. М. Наука. 2002. 368 с.
7. Крижановская О.О., Бородина Е.В., Карпов С.И. // Сорбиионные $u$ хроматографические прочессы. 2012. № 12. C. 583-591.

8. Мироненко Н.В., Брежнева Т.А., Пояркова Т.Н., Селеменев В.Ф. // Хим.-фарм. журн. 2010. Т. 44. № 3. С. 48-51.

9. Mitra S., Dunga S.R. // Journal Agricultural and Food Chemistry. 1997. No 45. pp. $1587-1595$.

10. Мироненко Н.В., Смусева С.О., Брежнева Т.А., Селеменев В.Ф. // Журн. физической химии. 2016. Т. 90. № 12. С. 1-6.

11. Мироненко Н.В., Брежнева Т.А., Селеменев В.Ф., Столповская А.А. // Вестник Воронеж. гос. ун-та. Серия: Химия. Биология. Фармация. 2015. № 1. С. 16-21.

12. Sing K.S.W., Everett D.H., Haul R.A.W. et al. // Pure and Applied Chemistry. 1985. Vol. 57. No 4. pp. 603-619. 
13. Когановский А.М., Клименко Н.А. Физико-химические основы извлечения поверхностно-активных веществ из водных растворов и сточных вод. Киев. Наукова думка. 1978. 174 с.

14. Alberti G., Amendola V. // Coordination Chemistry Reviews. 2012. Vol. 256. pp. 28-45.

15. Толмачев А.М. Термодинамика адсорбции газов, паров и растворов. Химический факультет МГУ. 2012. 240 с.

16. Мироненко Н.В., Брежнева Т.А., Селеменев В.Ф. // Журнал физической химии. 2013. T. 87. № 3. C. 387-390.

17. Freundlich H.M.F. // J. Phys. Chem. 1906. Vol. 57. pp. 385-471.

\section{Description of the sorption isotherm of triterpene saponin on natural sorbents}

\author{
Mironenko Natalia V., Smuseva Svetlana O., \\ Kotsareva Tatiana V., Selemenev Vladimir F. \\ Voronezh State University, Voronezh
}

There are quite a number of papers focusing on the sorption of bioactove compounds on syntheric and natural sorbents. These compounds include triterpenoid saponins which are commonly used as natural medicinal products. In this study we analysed, whether the existing models can be applied to interpret the experimental results of the adsorption of saponin on natural sorbents.

The object of the study was a saponin sample Quillaja Saponaria Molina produced in the USA. Chitosan, produced by OOO Pharmakon Production (St.Petersburg), is an aminopolysaccharide, a derivative of a linear polysaccharide, whose macromolecules are composed of $\beta$-(1-4)-linked D-glucosamine and N-acetyl-Dglucosamine. It is often used as biologically active food supplements. Activated charcoal produced by OAO Pharmastandart-Leksredstva was used as a carbon-based material. The sorption equilibrium in the «saponin - chitosan» and «saponin - charcoal» systems were studied at a temperature of $298 \pm 2 \mathrm{~K}$ under static conditions using variable concentrations.

During the experiments the isotherms of saponin on chitosan and on activated charcoal were obtained. The first regions of both isotherms are linear. The interaction between saponin and chitosan is based on the ion coordination interaction with the ammonium group of the polysaccharide. The interaction with the carbon-based material is determined by long-range hydrophobic forces which cause the association of saponin molecules and attract them to the hydrophobic surface of the sorbent. The second regions are different for the two isotherms. There is an inflection point followed by a plateau on the chitosan isotherm and a local minimum in the areas of concentration on the carbon-based material isotherm. This is followed by an increase in the sorption parameter on both isotherms. The nonlinearity of the isotherm in this region demonstrates that there are two opposite processes taking place at the same time: the formation of micelles and adsorption on the surface of the sorbent, which are characterised by the energy of adsorption and the energy of association. Depending on the values of these energies, there is either a step to a plateau or a local minimum on the curve. The latter is observed when the energy of micelle formation prevails over the adsorption energy. In the third region there is a sharp increase in the sorption parameters, which is accounted for by the formation of lamellar aggregates in the adsorption layers.

Taking into account the shape of the equilibrium curves, the experimental results were modelled using basic adsorption isotherms. The values of sorption parameterswere calculated. Since the correlation coefficients $\left(\mathrm{R}^{2}\right)$ are large, we can use Henry's law to conduct a quantitative description of the first region of the chitosan isotherm and the BET method to analyse the whole isotherm, as it takes into account the multilayer character of the adsorption process.

The adsorption of saponin on the carbon-based material is described by Langmuir equation in the range of $0.02-1 \mathrm{mmol} / \mathrm{dm}^{3}$ and the BET equation in the range of $2-17 \mathrm{mmol} / \mathrm{dm}^{3}$. The obtained results comply with the proposed models of adsorption of saponin on natural sorbents, and can serve as an explanation for a possible change in its pharmacokinetic properties in the immobilized state.

Keywords: Saponin, chitosan, charcoal, sorption, association, Henry's law, Langmuir isotherm, the Freundlich equation, the BET method, Redlich-Peterson isotherm 


\section{References}

1. Kuznecov V.A., Slivkin A.I., Lapenko V.L., Bolgov A.A., Vestnik MITHT, 2009, No 3, pp. 97-102.

2. Kotova D.L., Fam Thi Gam, Krysanova T.A., Vasil'eva S.YU. et al., Sorbtsionnye $i$ khromatograficheskie protsessy, 2014, Vol. 14, No 4, pp. 572-577.

3. Hostettmann K., Marston A. Saponins, Cambridge: Cambridge University Press, 1995, $548 \mathrm{p}$.

4. Atamanova S.A., Brezhneva T.A., Slivkin A.I., Nikolaevskij V.A. et al., Khim.farm. zhurn., 2005, Vol. 39, No 12, pp. 29-31.

5. Kovalenko G.A., Kuznecova E.V., Khimiko-farmacevticheskij zhurnal, 2000, Vol. 34, No 6, pp. 45-49.

6. Skryabin K.G. Khitin i khitozan: poluchenie, svojstva i primenenie / Pod red. K.G. Skryabina, G.A. Vihorevoj, V.P. Varlamova, M., Nauka, 2002, 368 p.

7. Krizhanovskaya O.O., Borodina E.V., Karpov S.I., Sorbtsionnye $i$ khromatograficheskie protsessy, 2012, No 12, pp. 583-591.

8. Mironenko N.V., Brezhneva T.A., Poyarkova T.N., Selemenev V.F., Khim.-farm. zhurn., 2010, Vol. 44, No 3, pp. 48-51.

9. Mitra S., Dunga S.R., Journal Agricultural and Food Chemistry, 1997, No 45, pp. 1587-595.

10. Mironenko N.V., Smuseva S.O., Brezhneva T.A., Selemenev V.F., Zhurn. fizicheskoj khimii, 2016, Vol. 90, No 12, pp. 16.

\footnotetext{
Мироненко Наталья Владимировна - к.Х.н., ассистент кафедры аналитической химии Воронежского государственного университета, Воронеж, т.(473)2208-932

Смусева Светлана Олеговна - аспирант химического факультета Воронежского государственного университета, Воронеж, т.(473)2208-932

Коцарева Татьяна Викторовна - магистрант химического факультета Воронежского государственного университета, Воронеж

Селеменев Владимир Федорович - д.х.н., проф., зав. каф. аналитической химии химического факультета Воронежского государственного университета, Воронеж
}

11. Mironenko N.V., Brezhneva T.A., Selemenev V.F., Stolpovskaya A.A., Vestnik Voronezh. gos. un-ta. Seriya: Khimiya. Biologiya. Farmaciya, 2015, No 1, pp. 16-21.

12. Sing K.S.W., Everett D.H., Haul R.A.W. et al., Pure and Applied Chemistry, 1985, Vol. 57, No 4, pp. 603-619.

13. Koganovskij A.M., Klimenko N.A. Fiziko-khimicheskie osnovy izvlecheniya poverhnostno-aktivnyh veshchestv iz vodnyh rastvorov i stochnyh vod. Kiev, Naukova dumka, 1978, 174 p.

14. Alberti G., Amendola V., Coordination Chemistry Reviews, 2012, Vol. 256, pp. 28-45.

15. Tolmachev A.M. Termodinamika adsorbcii gazov, parov i rastvorov. Khimicheskij fakul'tet MGU, 2012, 240 p.

16. Mironenko N.V., Brezhneva T.A., Selemenev V.F., ZHurnal fizicheskoj khimii, 2013, Vol. 87, No 3, pp. 387-390.

17. Freundlich H.M.F., J. Phys. Chem., 1906, Vol. 57, pp. 385-471.

18. Brunauer S., Emmett P.H., Teller E., J. Am. Chem. Soc., 1940, Vol. 62, pp. 1723-1732.

19. Redlich O., Peterson D.L.A. J. Phys. Chem., 1959, Vol. 63, pp. 1024-1026.

20. Allen S.J., Gan Q., Matthews R., Johnson P.A., Bioresour. Technol., 2003, Vol. 88, pp. 143-152.

21. Kocareva T.V., Smuseva S.O., Mironenko N.V., Selemenev V.F., Sovremennye problemy himicheskoj nauki i farmacii: sbornik materialov 6-j Vserossijskoj konferencii s mezhdunarodnym uchastiem, CHeboksary, 2017, pp. 58-59.

Mironenko Natalia V. - the assistant of the department of Analitical chemistry, Voronezh State University, e-mail: natashamir@yandex.ru

Smuseva Svetlana O. - the graduate student of chemical faculty, Voronezh State University, Voronezh, e-mail: svetlana_smuseva@mail.ru

Kocareva Tatiana V. - the master of chemical faculty, Voronezh State University, Voronezh

Selemenev Vladimir F. - the professor, head of the department of Analitical chemistry, Voronezh State University, Voronezh 